\title{
Using Reading Inventory as a Learning Tool
}

\author{
Siao-cing Guo ${ }^{1}$ \\ ${ }^{1}$ National Taipei College of Business, Taiwan \\ Correspondence: Siao-cing Guo, Department of Applied Foreign Languages, National Taipei College of \\ Business, Taipei, Taiwan. Tel: 886-2-2322-6418. E-mail: schu@webmail.ntcb.edu.tw
}

\author{
Received: October 17, 2012 Accepted: November 8, 2012 Online Published: December 12, 2012 \\ doi:10.5539/elt.v6n1p122 URL: http://dx.doi.org/10.5539/elt.v6n1p122
}

\begin{abstract}
Standardized testing is widely utilized to determine the levels of children's learning achievement. There has been a constant debate on how accurately standardized tests reflect children's achievement. Many practice teachers struggle with teaching to the test to meet the national criteria. An elementary teacher questioned the accuracy of the standardized test and worked with the researcher to seek an alternative form of reading assessment to determine the student's reading level. The researcher utilized reading inventory, student's learning records, teacher's and student's feedback, and a parental conference to inquire into the issue. The results revealed that although the child was categorized as a low-level reader, the child was a capable reader, only that he read too quickly and tended to miss details of the information he was reading. He adopted reading strategies to assist his reading. This study demonstrated that alternative assessing can be a valuable learning tool for teachers and students.
\end{abstract}

Keywords: alternative assessment, reading inventory, reading strategy, reading process, standardized test

\section{Introduction}

Standardized tests are generally regarded as providing effective evidence for evaluating children's reading achievement. However, in real classroom environments, many practice teachers struggle with the claim that high-stakes tests are the most accurate indicator of children's literacy achievement (Lawrence, Rabinowitz, \& Perna, 2009; White, Sturtevant, \& Dunlap, 2003). A primary teacher in the Los Angeles area, found that one of her students ranked at a very low percentile in the reading section on the standardized test. She questioned if standardized tests could truly reflect her students' reading abilities and sought an alternative assessment to measure their reading progress. An alternative assessment using a qualitative method can serve as a learning tool about children's literacy development for teachers, students, and parents. An opportunity allowed me to participate in the assessment of a particular child, Andrew (pseudonym) from her class. The researcher used reading inventory to observe the child's reading ability and strategies. Utilizing student's learning records from the teacher, the interview with the student, and a parental conference, we were able to put together the pieces of a puzzle to assess Andrew's reading development. At the end, we had a much better understanding of Andrew's comprehension, strategies, and history of reading, as well as his home reading experience.

\section{Literature Review}

Educators and researchers have been seeking ways for equitable assessment to inform students' learning outcomes. However, the ramification of factors such as "language, culture, educational background, and opportunity" has made it challenging to determine an equitable assessment measurement (Beaumont, Valenzuela, \& Trumbull, 2002). Standardized testing has long been regarded as a fair and objective method for student evaluation on learning achievement. The public also believes that standardized tests "are the only legitimate indicator of a school's instructional effectiveness" (Popham, 2005, para. 1); thus, it has been widely practiced for decades. Test scores are used for ranking students as well as schools. Because of its wide acceptance, the researcher has observed what amounts to a mania of testing preparation both inside and outside of classroom. Teachers reported directing time and energy to teach to the tests and testing strategies (Abrams, Pedulla, \& Madaus, 2010). Schools have become an institution to brew test-takers.

Standardized tests are designed under the assumption that students are the same. They are taught the same information, and they are all supposed to respond with the same answers to meet the criteria set up by the education system. The types of tests that are used contain multiple-choice and fill-in-the-blank statements they 
are to complete with fixed answers, thus generating easily identified correct/incorrect results (Beaumont, Valenzuela, \& Trumbull, 2002). It is as if all students gain knowledge in exactly the same way. Therefore, many teachers regard standardized tests to be of little value in the understanding of language learners, and they do not believe this type of test reveals what their students truly capable of (Jia, Eslami, \& Burlbaw, 2006). McNeil revealed that standardized testing actually "reduces the quality and quantity of what is taught and learned in schools" (McNeil, 2000, p. 3).

There has long been criticism on educational evaluation based solely on standardized testing. A few key educators and researchers strongly advocate the incorporation of alternative ways of assessment (Valencia, Hieber, \& Afflerbach, 1994; Wiggins, 1993). Classroom practice requires assessing methods that are more informative and more useful (Bagnato, 2005) to both teachers and students.

While standardized tests report on how well students score, alternative approaches in assessment can demonstrate what students learn, their learning process, and "where progress can be made" (Baker, 1996, p. 270) In recent years, formative assessing methods which inform learning process rather than learning results are widely adopted (Charvade, Jahandar, \& Khodabandehlou, 2012). Because it provides information on what students actually did, how they did, and what they were capable of doing. Observations, learning records, and portfolios are examples of alternative assessment. An alternative assessment approach involves the analysis of student performance on a variety of different tasks and in different situations, and usually extends over a period of time. It aligns with the social constructivist's view on learning and assessing (Porcaro, 2011; Splitter, 2009), which perceives knowledge as a whole and what knowledge means to each individual and how each individual interacts with knowledge. Students are assessed by their individual progress toward generally agreed upon goals instead of being compared to one another (Thomas, 2000). The emphasis of an alternative assessment approach focuses on process rather than on products. McMillan (2003) suggests, it is better teachers choose classroom assessment based on goals for students rather than to follow large-scale standardized criteria. Assessment needs to go beyond standardized test format in order to accommodate individual differences.

\section{Student's Background}

Location: An Elementary School in the Los Angeles area

Description of the class: A mixed grade class. Sometimes some students join other classes for different activities, and instructions.

Description of the child: Andrew was an eight-year-old third grade student. He came from India at the age of two. His parents are both bilingual. The primary language Andrew speaks is English. However, he would like to learn the language his parents speak.

\section{The Experiment}

\subsection{Preparation}

Before the assessment began, we explained to the parents the objective and procedures of the experiment. Parents were enthusiastic about an alternative assessing method, which was more in depth. Three pull-out reading sessions were arranged to inquire into Andrew's reading process. At the end of the experiment, a teacher meeting and a parental conference was arranged to present the results of findings on Andrew's reading. The results of the parental conference were described in the three-way meeting.

\subsection{Reading Inventory}

To understand how much he understood what he had read, the researcher adapted the prompt questions proposed in a major point interview for readers from Mosaic of Thought by Keene and Zimmermann (1997, p. 228-235). The focused reading skills included schemas, inference, important ideas in the text as well as reading strategies.

After Andrew read the story, he was prompted with questions such as the following:

A. Important Ideas in the text

1. Can you tell me as much as you can about what you read?

2. What are the important ideas from the text?

3. What are the events happening in the story?

Who are the main characters in the story?

What did they do?

4. Is there a part you do not understand? 
B. Inference

1. What do you think the character would do next?

2. What do you think will happen in the next chapter?

3. After this happened, what will happen next?

C. Schemas

1. Have you seen or experienced anything similar to what happened in the story?

2. Is there anything in the story similar to your life?

D. Strategies

1. When you were reading, did you encounter any problems?

2. Is there anything you do not know?

3. What did you do to the part you do not know?

The books Andrew read during the assessment session were from Magic Tree House series. For each section the researcher met with Andrew for approximately fifteen to twenty minutes. The length of each session also depended on his attention span. First he read the book and then the researcher would ask him questions about the reading. To see if his comprehension was affected by the read aloud, the researcher had him read one chapter out loud and one chapter silently.

\section{Findings}

\subsection{Reading Sessions}

\subsubsection{The First Meeting}

Based on the notes collected from three reading sessions with Andrew, it was found that when Andrew talked about the main ideas of the story, he tended to recall the last information or event in the story he read, but left out the major events at the beginning and the mid part of the story. When asked what else happened in the story, he said, "nothing", but after providing him with prompts, he then was able to recall more details of the story. He retrieved events that happened in the story in addition to the main idea. One time, when he was stuck and didn't remember the story, the researcher pointed out a particular part on the pages which happened to contain illustrations. He could then recall the main ideas of the story.

Andrew was able to recite more of the story when he was prompted by verbal clues and visual clues such as an illustration. In fact, Andrew understood the reading more than he recalled the first and second time. He often referred to other books from the series that he had read earlier; thus, he was able to make good inferences. When asked if he experienced any difficulties or problems, he responded that he knew everything, and there was no problem. Either he really understood everything or he might have been reluctant to reveal minor difficulties or problems. He often used strategies such as rereading. He paused when encountering words he was not clear on, but he still managed to read them.

Andrew appeared to have a short attention span. He was often fidgety and easily distracted by the surroundings. He turned around when he heard of a noise, and he looked up as people were walking by. He moved around and adjusted his posture during his reading time and the interview time. He even dropped the book on the ground a couple of times during reading or asked to be excused to the bathroom.

\subsubsection{The Second Meeting}

Considering Andrew's short attention span, the researcher divided a chapter into two halves. Andrew would read only half of the chapter at a time. However, with a shorter reading piece, Andrew still was unable to recite many details in the first half of the chapter. He seemed to have less patience and became even less focused on the second half. He recalled even fewer events from the second half. Foremost, he missed the main ideas of the chapter--democracy. It may have been that he did not understand the meaning of democracy. The concept of democracy can be too complex for an eight-year-old boy to comprehend. As he was reading, he stumbled on the word "unanimous," he asked for its pronunciation a couple of times. However, he figured out the meaning from the definition given in the later sentence. When asked about difficulties, he only pointed out the word unanimous, but nothing else.

Andrew's attention was still not focused at this time. He stopped reading a couple of times, and skipped to other pages to look at the pictures in later chapters. It seemed that he was anxious to find out the ending. 


\subsubsection{The Third Meeting}

Andrew brought a book to read in this section, a book he had read about a week prior to this meeting session. Since he had read it not long before, I assumed he might still be familiar with the story. But after just one week, he did not remember many details of the story. Although Andrew had read the story beforehand, it could have been that he was anxious to read through the book and did not pay attention to the details of the story. During the meeting section, he reread chapters 1 to 3 . When asked about the main idea of the story, he recalled only the last piece of information in the last chapter (3) he had just finished reading. It was only when he was asked more detailed questions that Andrew was able to recall more events in the chapters.

After reading more chapters and browsing through pictures in the book, he began to remember more of the story. He did reveal his preferences and dislikes about the book, and supported them with reasons. He said the king in the story was really cruel to people; therefore, he didn't like the king at all.

Several assumptions about Andrew's reading conditions were derived from the observation with Andrew's reading process. Although Andrew appeared to be inattentive from time to time, he was on his way to becoming a fluent reader. He had read many different books and expressed a desire to read more. Because of his desire to do additional reading, he tended to quickly devour the text without paying much attention to content details. He understood most of what he had read. At first he could not recall much of the story. The researcher prompted him with questions and clues; then he was able to recall details. He generally understood the major characters and events in the story; however, he sometimes missed ideas that have an underlying meaning. This may have something to do with the speed of his reading. Because he was anxious about finishing the book, although he read fluently, he demonstrated only surface-reading fluency. He did not allow time for grasping the underlying meaning. Since he often read very quickly, he did not retain much of the content until he was asked to think about it. He had a short attention span and did not concentrate as he read, which may have also led to his deficiency in detail comprehension. From the meeting notes, it also showed that Andrew was rather hesitant to indicate any reading problems or difficulties he experienced. Furthermore, the stories we read together were easy reading for Andrew. He understood most of the stories without much problem. When he encountered words he did not know, he would try to sound them out, and guessed their meaning. If he did not get the meaning, he would then just skip the word. He also used the rereading strategy when he stumbled on some words or phrases he was unsure of. Andrew constructed meaning through the text and related the content of the stories with his experience and feelings. It showed that he interacted with the text and adopted strategies such as guessing and making an inference from the context.

\section{Teacher's Perspectives}

According to the reading scale for K-3, Andrew was on the level of fluent reader 4.

Fluent reader 4 is a capable reader who now approaches familiar texts with confidence but still needs support with unfamiliar materials. Beginning to draw inferences from books and stories. Reads independently. Chooses to read silently.

From the teacher's point of view, Andrew had a good ability to read chapter books. He was able to read fairly difficult words with ease and quickly figure out the meaning of unfamiliar words. There were some questions about the extent to which he comprehended the reading. Andrew would choose a variety of reading materials in class, including picture books, easy chapter books and occasionally more advanced chapter books. He could read silently on his own. He did not stay with one book for several days; instead he went quickly from book to book. Sometimes, he was focused on his reading in the class time, but he was often distracted.

\section{Student's Perspectives}

Because of the teacher's suggestion, I arranged to share my findings with Andrew to find out if Andrew agreed with the findings. Andrew expressed high interest in reading. He claimed to comprehend almost all stories he read without any problem. He further stated that reading could help him learn more new things and different cultures and different ways of living. For instance, in ancient Greece, girls were not allowed to appear on stage. New knowledge inspired him to read more books. He also realized that he sometimes was not very focused during his reading. He said that he liked to look around. After our meeting, he set a goal for himself. He wanted to take more charge of his reading. He would monitor himself more and not look around so much. He could also use a Koosh Ball to help him concentrate. From the observations and interaction with Andrew, I found that Andrew was indeed on his path to becoming a fluent reader. The Magic Tree House series may be too easy for his level. Perhaps because of easiness, he was more careless with the reading content. It was time for Andrew to move onto more challenging books with more complicated content and a longer text. The longer text might also 
challenge his concentration. In terms of ways to strengthen his reading comprehension, it requires further professional input and research from children's reading specialists.

\section{Three-way Conferencing}

My conclusion still missed a few pieces of the puzzle. My findings reflected Andrew's reading of the Magic Tree House series, but they did not represent his reading comprehension of all types of reading. How Andrew did in class and his home reading still remained a mystery to me. So I met with Andrew's parents as well as the teacher to share our findings together. Both parents and the teacher agreed with my findings. They all thought that Andrew had a short attention span, and that it might be difficult for him to concentrate when he read. But according to the teacher, Andrew sustained his reading longer, compared to his reading time the previous year. By the beginning of this term he had switched to silent reading, and he was able to read for a longer period. According to Andrew's parents, Andrew did some reading almost every day, with a minimum of twenty minutes each reading time. Every night before he went to bed, one of his parents would read to him. Both of his parents were instructors at the college level. They were very concerned about learning development.

\section{Discussion and Conclusion}

Last year, Andrew took the standardized test for the first time; the results of the scores placed him in the low percentile, especially in reading. The test results had led the teacher and parents to feel frustration. The teacher and the parents felt that the scores did not reflect Andrew's reading comprehension or his performance in the classroom. If based only on the standardized test score, Andrew would not be classified as an experienced reader at all. The tests contain reading comprehension questions in the multiple choice form. They do not show how a child reads and how the child interacts with the text. However, an alternative assessment measurement like the one conducted in this study has shown that Andrew was a capable reader, and it revealed the interest he demonstrated in reading. He was reading for curiosity and knowledge, not for tests. The parents and the teacher felt very positively about this form of alternative assessment of the child's reading process. Unfortunately, tests, especially standardized testing, are inevitable in today's learning environment and they will have an influence throughout a child's academic life. Andrew would have to face more standardized tests later on. He needs to learn how to "take" the reading test, develop "testing skills" to meet the required reading standards for each level. To help Andrew perform better on standardized reading tests, the teacher would have to include more similar types of test practice in class. In addition, the parents could have Andrew work on sample tests at home as well. The time spent on learning to take tests should be directed to the development of high-order critical thinking and literacy skills as the mastery of these skills is key to succeed in life in the $21^{\text {st }}$ century (Lawrence, Rabinowitz, \& Perna, 2009).

Standardized testing does not show how children read and how they interact with the reading. It fails to recognize diverse backgrounds and multiple intelligences of learners. Therefore, it may not be the best answer to enhance instruction and learning (Madeja, Dorn, Sabol, 2004). Nonetheless, standardized testing is deeply rooted in the educational system in the U.S., and it has a similar impact in Taiwan. It has been a major form of assessment and a predictor of students' achievement for several decades. Therefore, to change people's perceptions of testing and to implement an alternative form of assessment can be a daunting task (Corcoran, Dershimer, \& Tichenor, 2004). Researchers and educators need to conduct more empirical research and present ample positive evidence to convince policy makers and educational officials. Administrators and teachers need to be well informed in regard to an alternative form of assessment and ways to implement it. Alternative assessment is a measure to assist the evaluation process of learners. Although some teachers already began to include an alternative assessment, the state/national standardized tests continue to dominate classroom instruction and learning. Many teachers feel compelled to teach to the tests. Consequently, alternative assessment may not be an advantage in classroom practice but a burden for both teachers and students.

Standardized tests do not reflect all aspects of knowledge or the abilities of learners as a whole. They are not entirely meaningless. The intention of this study was not to condemn standardized testing. The standardized test results are still a valid indicator of students' skills on the test performance. Alternative assessment, on the other hand, is not the 'magic bullet' for educational evaluation. The issues of assessment are "too complex and it is closely related to complexity of classroom practice and the beliefs that drive public policy" (Black \& Wiliam, 1998, p.140). Assessment should not be merely an indication of students' level of knowledge but a way to inform and improve teaching and learning. It can provide more information about learning. It is also a valuable learning tool for teachers and students. Through alternative forms of assessment, a new learning dynamic emerges: teachers are students, and students are teachers as well (Freire, 1970). Broadening our views on assessment to incorporate potential assessing methods is a necessary step to improve the quality of education. Only when enough educators and the public recognize the shortcoming of standardized testing can education stop 
deteriorating (Popham, 2005). Alternative types of assessment can open another window for educators and researchers to gain a deeper understanding of our learners and the learning and teaching process that standardized tests results cannot offer.

\section{References}

Abrams, L. M., Pedulla, J. J., \& Madaus, G. F. (2010). Views from the classroom: Teachers' opinions of statewide testing program. Theory Into Practice, 42(1), 18-29.

Bagnato, S. (2005). The authentic alternative for assessment in early intervention: An emerging evidence-based practice. Journal of Early Intervention, 28(1), 17-22. http://dx.doi.org/10.1177/105381510502800102

Baker, C. (1996). Foundations of bilingual education and bilingualism. Clevedon: Multilingual Matters Ltd.

Beaumont, C., Valenzuela, J. S., \& Trumbull, E. (2002). Alternative assessment for transitional readers. Bilingual Research Journal, 26(2), 241-268.

Black, P., \& Wiliam, D. (1998). Inside the black box: Raising standards through classroom assessment. Phi Delta Kappan, Oct.

Charvade, K. R., Jahandar, S., \& Khodabandehlou, M. (2012). The impact of portfolio assessment on EFL learners' reading comprehension ability. English Language Teaching, 5(7), 129-139.

Corcoran, C. A., Dershimer, E. L., \& Tichenor, M. S. (2004). A teacher's guide to alternative assessment: Taking the first step. The Clearning House, 77(5), 213-216. http://dx.doi.org/10.3200/TCHS.77.5.213-218

Freire, Paulo. (1970). The pedagogy of the oppressed. New York: the Continuum Publishing Company.

Jia, Y., Eslami, Z. R., \& Burlbaw, L. M. (2006). ESL teachers' perceptions and factors influencing their use of classroom-based reading assessment. Bilingual Research Journal, 30(2), 407-430.

Keene, Elin O., \& Zimmermann, Susan. (1997). Mosaic of thought. Portsmouth, NH: Heinemann.

Lawrence, S. A, Rabinowitz, R., \& Perna, H. (2009). Reading instruction in secondary English language arts classrooms. Literacy Research and Instruction, 48(1), 39-64.

Madeja, S. S., Dorn, C. M., \& Sabol, F. R. (2004). Alternative assessment strategies for schools. Arts Education Policy Review, 105(5), 3-13.

McMillan, J. H. (2003). Understanding and improving teachers' classroom assessment decision making: Implications for theory and practice. Educational Measurement: Issues and Practices, 22(4), 33-44.

McNeil, L. (2000). Contradictions of school reform: Educational costs of standardized testing. New York: Routledge.

Popham, W. J. (2005). Standardized testing fails the exam. Retrieved from http://www.edutopia.org/standardized-testing-evaluation-reform

Porcaro, D. (2011). Applying constructivism in instructivist learning cultures. Multicultural Education \& Technology Journal, 5(1), 39-54.

Splitter, L. J. (2009). Authenticity and constructivism in education. Stud Philos Educ, 28(2), 135-151. http://dx.doi.org/10.1007/s11217-008-9105-3

Thomas, Sally. (1993). Rethinking assessment: Teachers and students helping each other through the sharp curves of life. Learning Disability Quarterly, 16, fall, 1993.

Thomas, Sally. (1994). Knowing learners-knowing ourselves: Teachers' perceptions of change in theory and practice resulting from inquiry into authentic assessment. Claremont, CA: Claremont Graduate School.

Thomas, Sally. (2000) "What are the assumptions about the knowledge we expect children to learn?" Unpublished manuscript, Claremont Graduate University, Claremont, CA.

Valencia, S. W., Hiebert, E. H., \& Afflerbach, P. P. (1994). Authentic reading assessment: Practices and possibilities. Newark, DE: International Reading Association.

White, S., Sturtevant, E., \& Dunlap, K. (2003). Preservice and beginning teachers' perceptions of the influence of high stakes tests on their literacy-related instructional beliefs and decisions. Reading Research and Instruction, 42(2), 39-62. http://dx.doi.org/10.1080/19388070309558385

Wiggins, Grant P. (1995). Assessing student performance: Exploring the purpose and limits of testing. San Francisco: Jossey-Bass Inc. 